\title{
Application of hydraulic model in optimal operation of water supply pumping station
}

\author{
Hao $\mathrm{Fu}^{1}$, Jianjun Wang ${ }^{2,3}$, Weining Yuan ${ }^{1}$, Chunsheng Zhang ${ }^{1}, \mathrm{Hang}_{\mathrm{Li}}{ }^{1}$, \\ Yang Feng ${ }^{1}$, Ming Zhao ${ }^{4, a^{*}}$, Tong Wang ${ }^{1,5}$, Panpan Huang ${ }^{5}$ \\ ${ }^{1}$ School of Environmental Science and Engineering, Chang'an University, Xi'an, 710054, China \\ ${ }^{2}$ School of Civil Engineering, Shandong University, Jinan, 250100, China \\ 3 Jinan Water Group Co., Ltd. Jinan, 250000, China \\ ${ }^{4}$ School of Municipal and Environmental Engineering, Harbin Institute of Technology, Harbin, \\ 150001, China \\ ${ }^{5}$ Tianjin Sambo Water Technology Co., Ltd. Tianjin, 300070, China \\ aemail:zhming1188@126.com
}

Keywords: Hydraulic Model; Optimal Operation of Pumping Station; Genetic Glgorithm; Hydraulic Simulation Software

\begin{abstract}
Through the J City water supply network hydraulic model, QF pumping station optimization scheduling scheme is designed by genetic algorithm. And analyzing the working days and weekends in different working conditions. After the implementation of the optimal scheduling scheme, the power consumption of the pump station is reduced by $5.21 \%$. The hydraulic model can be used to provide a high efficiency energy saving scheme for the optimal operation of pumping stations.
\end{abstract}

\section{Introduction}

Pump is an important general machinery. And energy consumption is relatively high owing to the need for pumping stations to pressurise the system in pressurised systems[1]. For advance of municipal infrastructure construction, the prediction of the water consumption is too large. At the same time, the selection of pump to be regard the highest daily flow rate as conditions, the head still has margin. In actual operation, the flow and head of the water supply pump are much lower than the designed flow and head in most of the time. The flow and head of the water supply pump are much lower than the designed flow and head in most of the time. Therefore, it is necessary to adjust the pump operating conditions for optimal scheduling. However, most of the water supply enterprises use manual scheduling method in the optimal operation which affects the water users in the water supply area.

Water network dynamic hydraulic model and the water quality model currently have been regarded as the most effective ways to analyze the network[2]. The establishment of hydraulic model for water distribution network by hydraulic simulation software can simulate the load of each node in water supply area. This method can be used to provide the operation conditions of water supply area for the water supply enterprises and to analysis the optimal scheduling for pumping station.

\section{Technical principles}

\section{The principle to saving energy of pump}

The unit consumption of water supply pump is as follows[3]: 


$$
W=\frac{H_{0}(Q, \mathrm{t})}{367 \times \eta_{\operatorname{MAx}}(Q, H)}+\left\{\frac{H_{0}(Q, \mathrm{t})}{367 \times \eta_{\operatorname{MAx}}(Q, H)} \times \frac{\triangle \eta(Q, H)}{\eta(Q, H)}\right\}+\frac{\triangle H(Q, \mathrm{t})}{367 \times \eta(Q, H)}
$$

The first part represents the minimum water consumption of pump, recorded as $W_{M I N}$; The second part represents the power consumption for per ton of water in current operating conditions, recorded as $\Delta W$. In $\Delta W$, the first part is the consumption of electric energy, the reason is that the working efficiency $(\eta(Q, H))$ has deviated from the maximum efficiency $\left(\eta_{\text {MAX }}(Q, H)\right)$ of the pump. The second part is the consumption of electric energy caused by the safety margin $(\Delta H(Q, t))$ of pump. Therefore, the method for the purpose of energy saving is making pump to run in high efficiency area by adjusting the pump discharge pressure.

However, pressure regulating has a certain impact on the users of water supply range. Using hydraulic model software can establish and check the hydraulic model of urban pipe network in the city, then simulating the load for each node in the water supply area of pumping station. Under the premise of ensuring water quantity and pressure for the user ,determining the optimal control conditions of the water supply pump.

\section{The optimization principle of hydraulic model}

For find the most effective optimization program, simulating the operation condition of pump through the genetic algorithm by the $\mathrm{WNW}^{\circledR}$ hydraulic simulation software. In GA, each solution is described as a group of chromosomes which contain a string of genes that corresponds to the controls of pressure for a pump during running period [4]. The purpose of pump optimization is to reduce efficiency deviation. Regulating pump head $(H)$ can change $\Delta \eta(Q, H)$.So the fitness function as follows:

$$
F I T^{\mathrm{k}}=\sum_{H}^{H_{M A X}}\left[\square \eta(\mathrm{Q} \square \mathrm{H})-\frac{H_{0}(\mathrm{Q}, \mathrm{t})}{367 \times \eta_{\operatorname{MAx}}(\mathrm{Q}, \mathrm{H})} \times \frac{\square \eta(\mathrm{Q} \square \mathrm{H})}{\eta(\mathrm{Q} \square \mathrm{H})}\right]^{2}
$$

For the optimization of pump, the important factors should be considered such as the most unfavorable position, main pipe, bursting position, water supply boundary and areas of terrain change. Therefore, the constraint conditions can be set as 1) the pressure of temporary pressure monitoring points is between the maximum and the minimum and 2) the water supply demand should be more than the minimum[5]:

$$
\begin{aligned}
& P_{\min }<P<P_{\max } \\
& Q>Q_{\text {min }}
\end{aligned}
$$

Using the temporary pressure monitoring points to control pump on the basis of not changing the status of the facilities and conditions, then making specific optimal scheduling scheme. At the same time, the optimization of pump should satisfy the requirements of water demand and pressure for user. Making water pump to work in the high efficient area, balancing the pressure of the pipe network, and then saving safety margin.

\section{Technical solution}

\section{Overview of pumping station}

Taking QF pump station in J city as an example to study the application of water supply network hydraulic model in optimal operation of pumping station.

The water supply capacity of QF pumping station which contains four pumps is $40 \mathrm{kt} / \mathrm{d}$. The parameters of pump are shown in Tab.1, and the curve of $Q-H$ and $Q-\eta$ for pump in parallel operation are shown in Fig.1. 
Tab.1 Pump parameters

\begin{tabular}{|c|c|c|c|c|c|c|c|}
\hline Number & $\begin{array}{l}\text { Electromotor } \\
\text { model }\end{array}$ & $\begin{array}{c}\text { Capacity } \\
\text { (KW) }\end{array}$ & $\begin{array}{c}\text { Rated } \\
\text { current }(\mathrm{A})\end{array}$ & Model of pump & $\begin{array}{l}\text { Rated } \\
\text { flow } \\
\left(\mathrm{m}^{3} / \mathrm{h}\right)\end{array}$ & $\begin{array}{l}\text { Rated } \\
\text { head } \\
(\mathrm{m})\end{array}$ & $\begin{array}{c}\text { Boot disk } \\
\text { model }\end{array}$ \\
\hline $1 \#$ & YE3-355M1-4 & 220 & 387 & KPS90-200-T & 800 & 72 & Self-Starting \\
\hline 2\# & YE3-355M1-4 & 220 & 387 & KPS90-200-T & 800 & 72 & VVVF \\
\hline 3\# & YE3-355M2-4 & 250 & 440 & KPS75-250-T & 1000 & 62 & Self-Starting \\
\hline 4\# & YE3-355M2-4 & 250 & 440 & KPS75-250-T & 1000 & 62 & VVVF \\
\hline
\end{tabular}
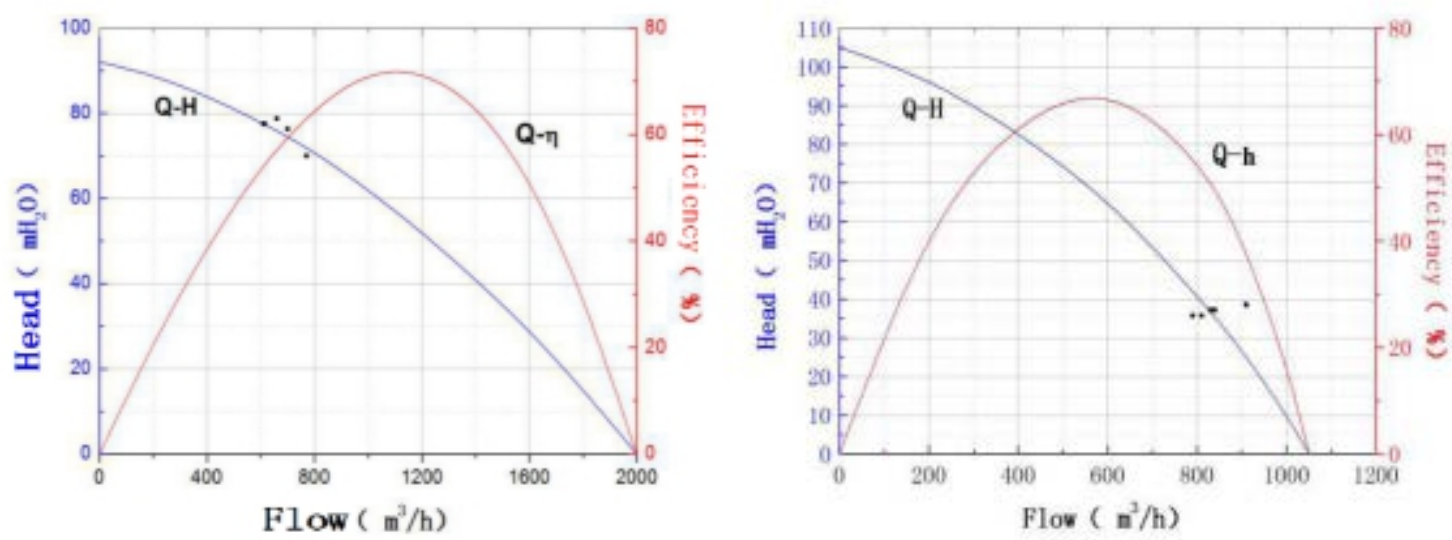

Fig.1 Actual characteristic curve of pump

(1\# and 2\# pump on the left,3\# and 4\# pump on the right. Black spot is the actual operating point.)

From Fig.1, the actual head of $1 \#$ and $2 \#$ is $78 \mathrm{~m}$, the efficiency is $60 \%$; the actual head of $3 \#$ and $4 \#$ pump is $35 \mathrm{~m}$, the efficiency is $28 \%$. Therefore, the pumping station has great potential for energy saving.

In order to use the hydraulic model to simulate the pumping station, firstly, it should ensure the minimum water supply demand for user, and then the pressure of main pipe monitoring points and the most unfavorable point of water supply range should be greater than the specified pressure. Simulating and analysising optimal factory pressure of pump by genetic algorithm. The data is shown in Fig. 2 after 1000 iterations. The maximum optimal factory pressure of the pumping station is $68 \mathrm{~m}$, the minimum is $60 \mathrm{~m}$.

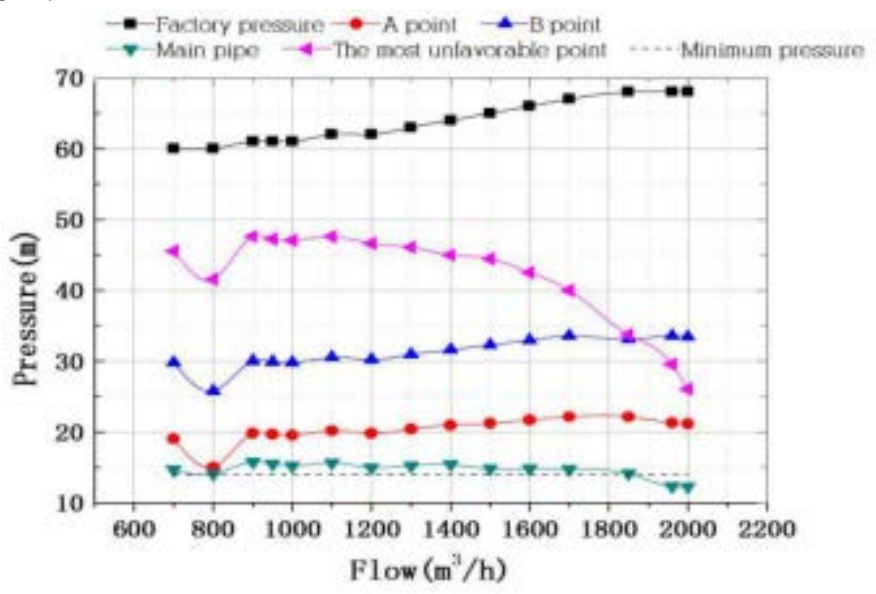

\section{Optimization scheme}

Fig.2 Optimal pressure of pumping station by hydraulic model

Firstly, the optimal dispatching of water supply network should ensure the requirement of water quantity, pressure and water quality for user. And then, taking methods to pursue the economic benefits of pipe network.

According to the optimal station pressure by the hydraulic model simulation, energy saving is implemented by time periods. Peak period of water supply demand does not implement energy-saving work, implementing the energy-saving work in low peak period of water supply demand. Specific programs are shown in Tab.2. 
Tab.2 Energy-saving implementation of the optimization program

\begin{tabular}{ccc}
\hline Time & Factory pressure $(\mathrm{m})$ & Control point pressure $(\mathrm{m})$ \\
\hline 1:00-6:00 & 60 & $13-15$ \\
7:00-12:00 & 68 & $14-17$ \\
13:00-17:00 & Scheduling according to the & $13-15$ \\
18:00-22:00 & actual situation & $14-17$ \\
23:00-24:00 & 68 & $13-14$ \\
\hline
\end{tabular}

\section{Data analysis}

\section{Results}

The consumption for tons of water by energy saving before and after project implementation as shown in Tab.3.

Tab.3 Comparison of power consumption before and after energy saving

\begin{tabular}{|c|c|c|c|}
\hline Number & Date & $\begin{array}{c}\text { The average } \\
\text { consumption for tons } \\
\text { of water }\left(\mathrm{kWh} / \mathrm{km}^{3}\right)\end{array}$ & $\begin{array}{c}\text { The percentage of saving } \\
\text { energy consumption } \\
(\%)\end{array}$ \\
\hline \multirow{4}{*}{$\begin{array}{c}\text { Before } \\
\text { implementation }\end{array}$} & December ,2014 & 255.81 & - \\
\hline & January ,2015 & 259.01 & - \\
\hline & February ,2015 & 265.54 & - \\
\hline & March, 2015 & 258.86 & - \\
\hline After implementation & & 246.27 & 5.21 \\
\hline
\end{tabular}

From tab.3, the optimal scheduling scheme can reduce the energy consumption by $5.21 \%$ compared with the original experience method, and the advantage of the method are obvious.

\section{Energy saving analysis under different conditions}

Using two different water supply conditions as example. Water supply demand, power consumption for tons of water and pipe network pressure as factors were compared before and after project implementation. As shown in Fig.3 5.

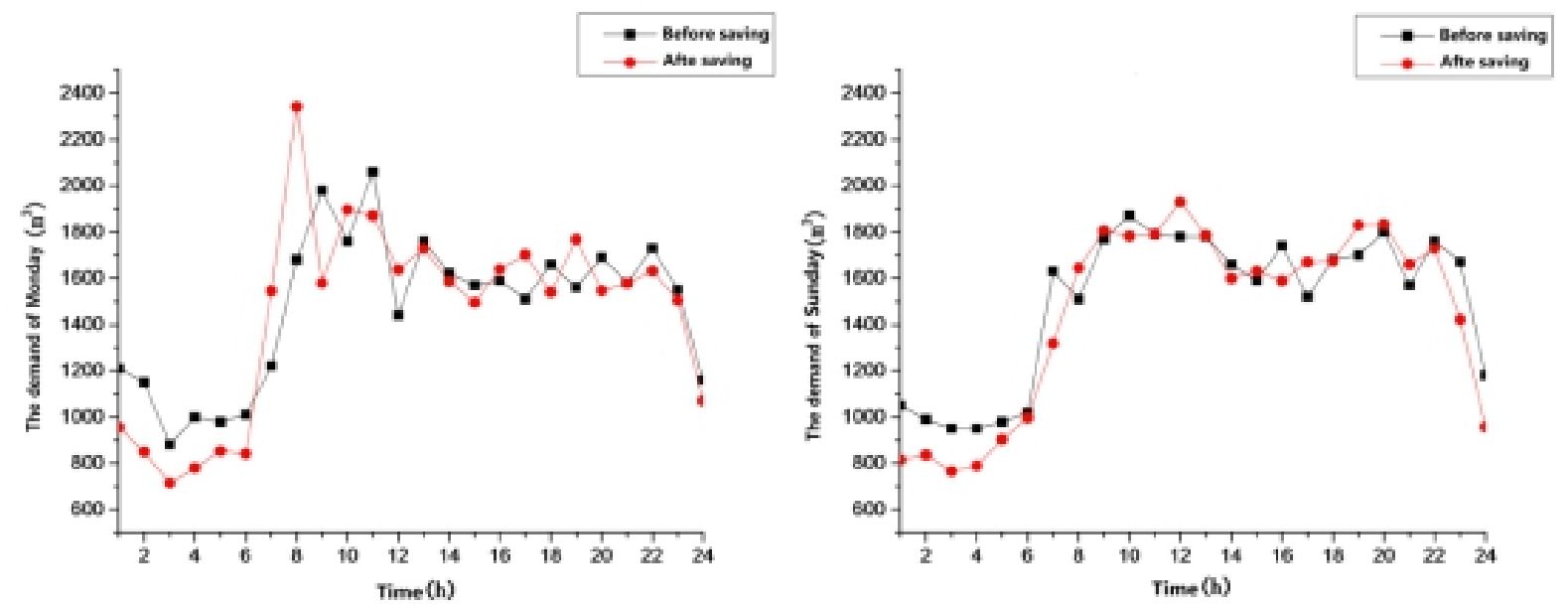

Fig.3 Comparison of water supply demand on Monday and Sunday 

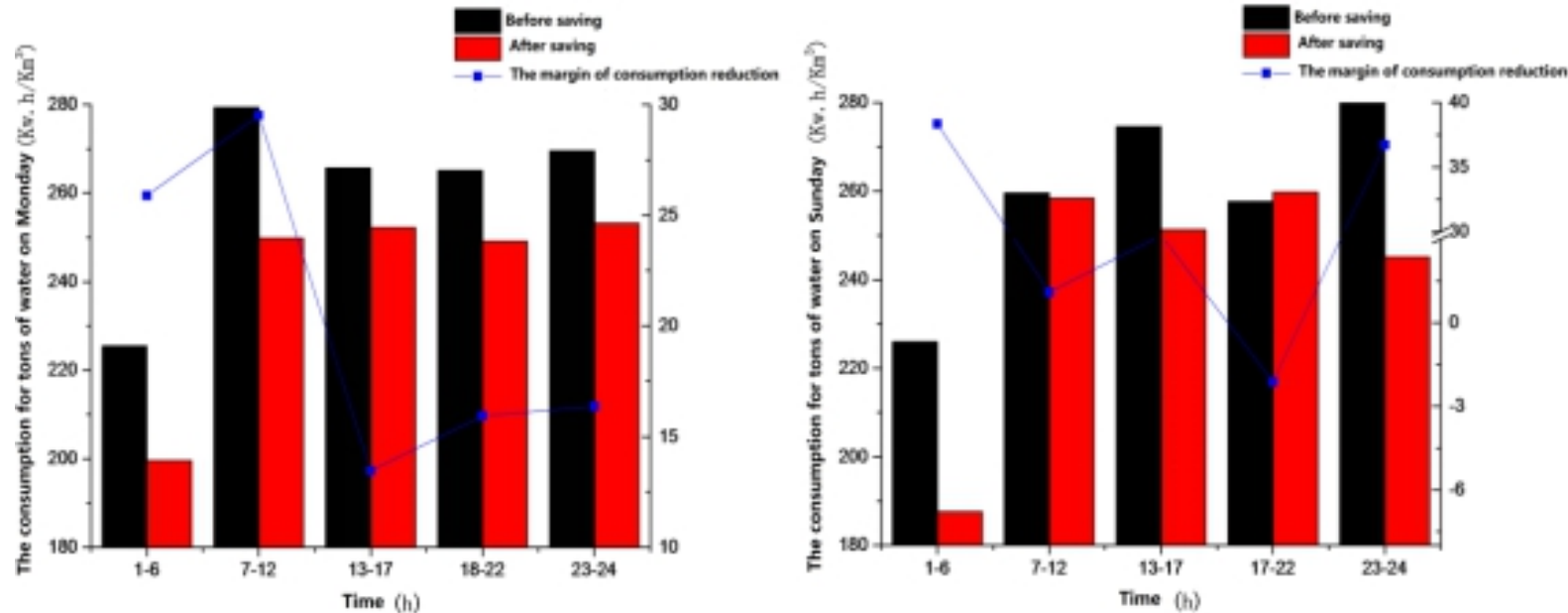

Fig.4 Comparison of power consumption on Monday and Sunday
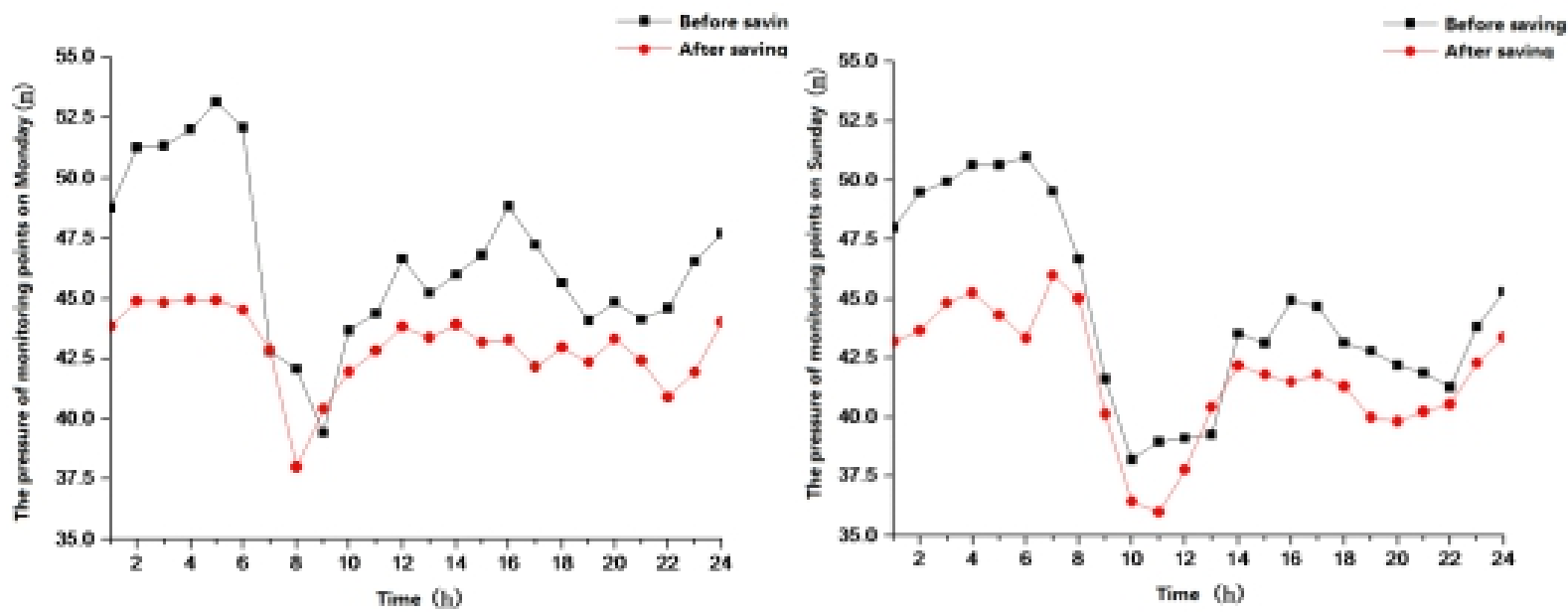

Fig.5 Comparison of pressure on Monday and Sunday

From the analysis of graph, the daily water supply capacity of the plant is basically unchanged before and after project implementation. In the case of reducing the factory pressure, the pressure of most unfavorable pressure monitoring point has declined. However, it can still meet the minimal pressure for compulsory provisions. In this case, the electricity consumption of water plant has decreased, and the energy saving effect of the method are very good.

\section{Conclusions}

During the period of energy saving, the optimal scheduling scheme can reduce the energy consumption by $5.21 \%$. The basic electricity price is $0.71 \mathrm{RMB} / \mathrm{kWh}$. Compared with 2013 , the value of saving energy is $186632.49 \mathrm{RMB} / \mathrm{km}^{3}$. And compared with 2014 , the value of saving energy is $137050.93 \mathrm{RMB} / \mathrm{km}^{3}$. It can provide a theoretical basis for the optimal operation of pump by the hydraulic model to analyze the hydraulic conditions of the network. It can provide a feasible and superior energy saving program.

\section{Acknowledgments}

This work was supported by a grant from the National Key Technologies R \& D Program of China during the $12^{\text {th }}$ Five-Year Plan Period (No.2014ZX07406003). And special thanks to Professor Hongbin Zhao of Harbin Institute of Technology. In addition, our classmates of Chang' an University and colleagues of Sambo also given us a lot of helps in learning and in life. 


\section{Reference}

[1] Juan I. Corcoles,Jose M.Tarjuelo,Miguel A. Moreno.Methodology to improve pumping station management of on-demand irrigation networks[J]. Biosystems Engineering.144(2016)94-104.

[2] Yue Xu,Xiao-yu Zhang. Research on pressure optimization effect of high level water tank by drinking water network hydraulic model[J]. Procedia Engineering.31(2012)958-966.

[3] The development of technological progress in 2010 and the vision objectives in 2020 for urban water supply industry, China.

[4] Seyed Mohsen Sadatiyan Abkenar, Samuel Dustin Stanley, Carol J. Miller, Donald V,Chase, Shawn P. McElmurry. Evaluation of genetic algorithms using discrete and continuous methods for pump optimization of water distribution systems[J]. Sustainable Computing: Informatics and Systems.8(2015)18-23.

[5] S.-C. Georgescu, A.-M. Georgescu. Application of HBMOA to pumping stations scheduling for a water distribution network with multiple tanks[J]. Procedia Engineering. 70(2014)715-723. 